\title{
Semi-Continuous Production of Tantalum Powder by Electronically Mediated Reaction (EMR)
}

\author{
Il Park ${ }^{1, * 1, * 2}$, Toru H. Okabe ${ }^{2}$, Oh Yeon Lee ${ }^{3}$, Chuel Ro Lee ${ }^{3}$ and Yoshio Waseda ${ }^{4}$ \\ ${ }^{1}$ Research Center of Advanced Material Development, Chonbuk National University, 664-141-ga, Dukjin-dong, Chonju 561-756, Korea \\ ${ }^{2}$ Institute of Industrial Science, The University of Tokyo, Tokyo 153-8505, Japan \\ ${ }^{3}$ School of Advanced Material Engineering, College of Engineering, Chonbuk National University, Chonju 561-756, Korea \\ ${ }^{4}$ Institute of Multidisciplinary Research for Advanced Materials, Tohoku University, Sendai 980-8577, Japan
}

An electronically mediated reaction (EMR) has been explored to produce tantalum powder semi-continuously by the calciothermic reduction of tantalum chloride $\left(\mathrm{TaCl}_{5}\right)$. $\mathrm{TaCl}_{5}$ feedstock and reductant calcium alloy were charged into electronically isolated locations in a molten $\mathrm{CaCl}_{2}$ bath at $1123 \mathrm{~K}$. The feed was freshly recharged three times, but the bath was reused without replenishment during four repeated reduction experiments. The current flow through an external path between the feed (cathode) and reductant (anode) locations was monitored. A current between 0.2 and 0.9 amps was measured during the reaction in the external circuit connecting cathode and anode. Tantalum powder was readily obtained after each experiment, but its purity decreased from $95 \%$ to $87 \%$ Ta as the run number increased. Tantalum powder obtained from EMR was fine compared with that of metal powder metallothermic reduction. Tantalum powder with low aluminum and nickel content was obtained although liquid $\mathrm{Ca}-\mathrm{Al}-\mathrm{Ni}$ alloy was used as the reductant. The results demonstrate the possibility of semi-continuous production of tantalum powder by the EMR without the direct physical contact between the feed and reductant. The mechanism of the calciothermic reduction of $\mathrm{TaCl}_{5}$ in the molten salt was discussed, using an isothermal chemical potential diagram.

(Received May 24, 2002; Accepted June 5, 2002)

Keywords: tantalum, metallothermic reduction, reduction process, thermodynamics, electrochemistry, metal powder

\section{Introduction}

Tantalum metal is widely used in the fields of electronics and chemical engineering, surgery, nuclear energy and space research $^{1)}$ as it has outstanding properties such as high melting point $(3269 \mathrm{~K})$, high corrosion resistivity and excellent workability. The increasing demand for tantalum is mainly due to growth of the high performance capacitor market for electronic devices.

Tantalum is commercially produced by sodiothermic reduction (Hunter process), ${ }^{2)}$ in which solid potassium heptafluorotantalate $\left(\mathrm{K}_{2} \mathrm{TaF}_{7}\right)$ is reduced with sodium metal in a molten salt medium so-called diluent. The overall reaction for this process can be expressed in the following equation:

$\mathrm{K}_{2} \mathrm{TaF}_{7}(l)+5 \mathrm{Na}(l) \rightarrow \mathrm{Ta}(s)+5 \mathrm{NaF}(l)+2 \mathrm{KF}(l)$.

Commercial tantalum reduction process is a batch-type process carried out in a metallic container sealed by argon gas at around $1073 \mathrm{~K}$. This process is suitable for the production of high-purity tantalum powder used for capacitor. ${ }^{3)}$ However, this process has a few intrinsic disadvantages: (1) batch-type reaction and large amount of salt used as reaction medium, which has to be discarded after the reduction process (2) difficult in controlling reaction sites and deposit morphology as the process is designed on the basis of direct physical contact between reactants (3) low productivity due to a long reduction time in a batch operation.

To overcome these disadvantages, Okabe and Sadoway ${ }^{4)}$ have introduced an idea of electronically mediated reaction (EMR) during metallotermic reduction. They experimentally showed the importance of electrochemical reaction at

\footnotetext{
${ }^{* 1}$ Corresponding author: E-mail: krparkil@yahoo.co.kr

${ }^{* 2}$ Present address: Institute of Industrial Science, The University of Tokyo, Tokyo 153-8505, Japan.
}

the metal-molten salt interface and transport of "electrons and ions" during sodiothermic reduction of $\mathrm{K}_{2} \mathrm{TaF}_{7}$. ${ }^{4)}$ The concept of EMR makes it possible to control morphology, location and impurity of deposit. The EMR concept was applied to the Kroll process which utilizes magnesiothermic reduction of titanium chloride $\left(\mathrm{TiCl}_{4}\right)$, and its usefulness has been confirmed. ${ }^{5-9)}$

The authors have reported the application of EMR to the tantalum reduction process that utilzed magnesiothermic reduction of tantalum chloride $\left(\mathrm{TaCl}_{5}\right) .{ }^{10)}$ They also demonstrated the EMR to the niobium reduction process that utilizes calciothermic reduction of niobium oxide $\left(\mathrm{Nb}_{2} \mathrm{O}_{5}\right)$. Recently, Park et al. ${ }^{11)}$ have studied the application of the EMR concept to the semi-continuous niobium reduction process, and the feasibility of the semi-continuous process that can radically reduce the amount of the diluent salt was demonstrated. In this study, a fine tantalum powder production by calciothermic reduction is investigated with the scope to establish the semi-continuous reduction process.

Up to now, the feeding system has been thought to be a bottleneck in continuous metallothermic reduction. In the present study, supplying a $\mathrm{TaCl}_{5}$ feedstock by repeated replenishment was attempted to demonstrate the feasibility of semi-continuous operation. In an effort to control the site and morphology of deposit in isothermal conditions, the reduction path and phase equilibrium were also studied in a threedimensional (3-D) isothermal chemical potential diagram for the $\mathrm{Ta}-\mathrm{Ca}-\mathrm{Cl}$ system.

\section{Electronically Mediated Reaction (EMR)}

Figure 1(a) shows the conventional representation of the calciothermic reduction of $\mathrm{TaCl}_{5}$ on the basis of reaction be- 
$\mathrm{TaCl}_{5}+5 \mathrm{Ca} \rightarrow 2 \mathrm{Ta}+5 \mathrm{CaCl}_{2}$

(a)

Feed material Reaction product

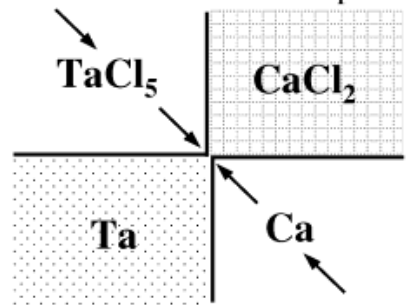

Metal deposit Reductant

(b)

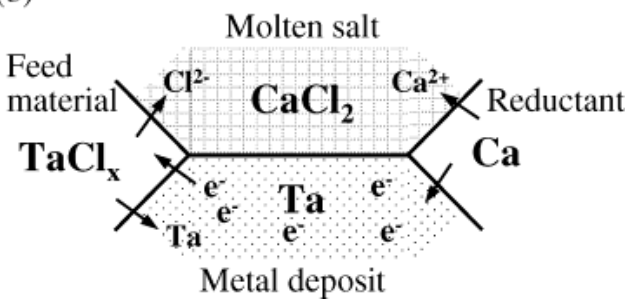

Fig. 1 (a) The conventional concept of caliothermic reduction of $\mathrm{TaCl}_{5}$ governed by reaction and transport of neutral species. (b) Electronically mediated reaction (EMR) during metallothermic reduction of $\mathrm{TaCl}_{5}$ through a metal/molten salt interface.

tween neutral species, as exemplified by the reaction:

$$
2 \mathrm{TaCl}_{5}+5 \mathrm{Ca} \rightarrow 2 \mathrm{Ta}+5 \mathrm{CaCl}_{2}
$$

Contact between $\mathrm{TaCl}_{5}$ and calcium is achieved by diffusion of the reactants through the production phase or in the reaction medium, and therefore the production phases are often considered as barriers to metallothermic reduction. ${ }^{12,13)}$ However, this is not a necessary condition. According to the concept of EMR, the reaction (2) can readily be divided into two electrochemical steps:

$$
\begin{aligned}
& \text { Location } 1: 5 \mathrm{Ca} \rightarrow 5 \mathrm{Ca}^{2+}+10 \mathrm{e}^{-} \\
& \text {Location } 2: \mathrm{TaCl}_{5}+10 \mathrm{e}^{-} \rightarrow 2 \mathrm{Ta}+10 \mathrm{Cl}^{-}
\end{aligned}
$$

When an electrically conducting medium exists to facilitate electron transfer and when charge neutrality conditions are satisfied, reactions (3) and (4) can, in principle, proceed at different locations, as illustrated in Fig. 1(b). To maintain charge neutrality at the two locations, diffusion of $\mathrm{Ca}^{2+}$ and/or $\mathrm{Cl}^{-}$ ions must take place in the molten salt. The sum of the electrochemical reactions directly gives eq. (2). Therefore, the overall reaction is identical to the conventional representation using neutral species.

EMR can be classified into two types in terms of the pass way of electron transfer: long-range EMR (LR-EMR) and short range EMR (SR-EMR). ${ }^{4)}$ In LR-EMR, an electron is transported through the reactor wall or a metal deposit, whereas in SR-EMR, an electronically conducting molten salt transports electrons between reaction sites. The difference between conventional metallothermic reaction and EMR is wellexplained elsewhere. ${ }^{4,14,15)}$ Some essential points required for the present work are given below with the schematic reactions shown in Fig. 2.

The LR-EMR can be considered as a heterogeneous reac- (a) Conventional representation of metallothermic reduction

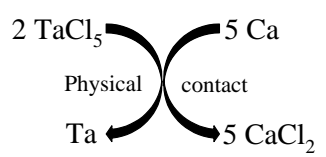

(b) Long-range electronically mediated reaction (LR-EMR)

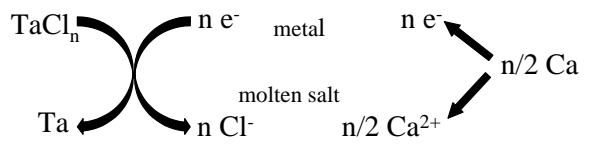

(c) Short-range electronically mediated reaction (SR-EMR) using ${ }^{\mathrm{Rm}+} / \mathrm{R}^{(\mathrm{m}+1)+1}$ redox couple. (e.g. $\mathrm{Dy}^{2+} / \mathrm{Dy}^{3+}$ )

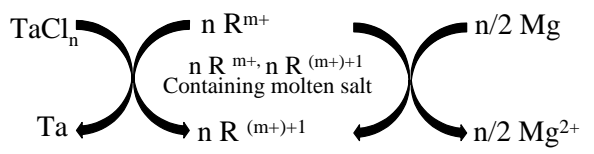

(d) Short-range electronically mediated reaction (SR-EMR) through electronically conductive molten slat.

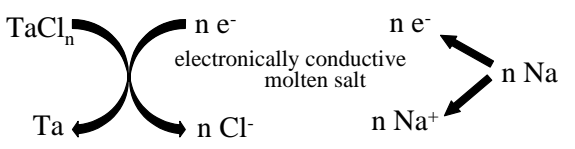

Fig. 2 Different mechanisms for the reduction of tantalum chloride by calcium in a molten salt.

tion, occurring at a metal surface (Fig. 2(b)). Therefore, it is possible to control the location of the deposit. ${ }^{7)}$ The SREMR is useful for powder formation because a homogeneous reaction occurs in the molten salt (Figs. 2(c) and (d)). The SR-EMR is generally rapid fast because the transport of the reductant can be easily accomplished in the molten salt. To test the usefulness of SR-EMR for producing metal powder, the reaction concept, schematically outlined in Fig. 2(c), can be employed by using a molten salt system that has the ability to emit electrons to reduce the feed material. It was experimentally demonstrated that molten salt containing $\mathrm{Dy}^{2+}$ has the ability to reduce titanium ions to produce fine titanium powder. ${ }^{7,8)}$ This halidothermic reduction is, in principle, useful for producing fine powder as the molten salt medium itself acts as a reductant. It is, however, difficult to find a suitable multivalent species for this type of reduction in the molten salt saturated with calcium metal because the redox potential involved metallic calcium is too low to establish the equilibrium between multivalent metal ions, as representatively shown in Fig. 2(c).

In the present study, the contribution of molten salt and metal, as ionic and electronic conductors respectively, is investigated for the calciothermic reduction of tantalum chloride. Calcium-saturated $\mathrm{CaCl}_{2}$ was employed to test this reaction because this molten salt medium is reported to have significant $\mathrm{Ca}$ and $\mathrm{CaO}$ solubilities in the molten phase. ${ }^{16,17)}$

\section{Experimental}

\subsection{Apparatus}

To monitor electronically mediated reaction (EMR) during semi-continuous production of tantalum metal powder by calciothermic reduction, reduction cells depicted in Fig. 3 were 


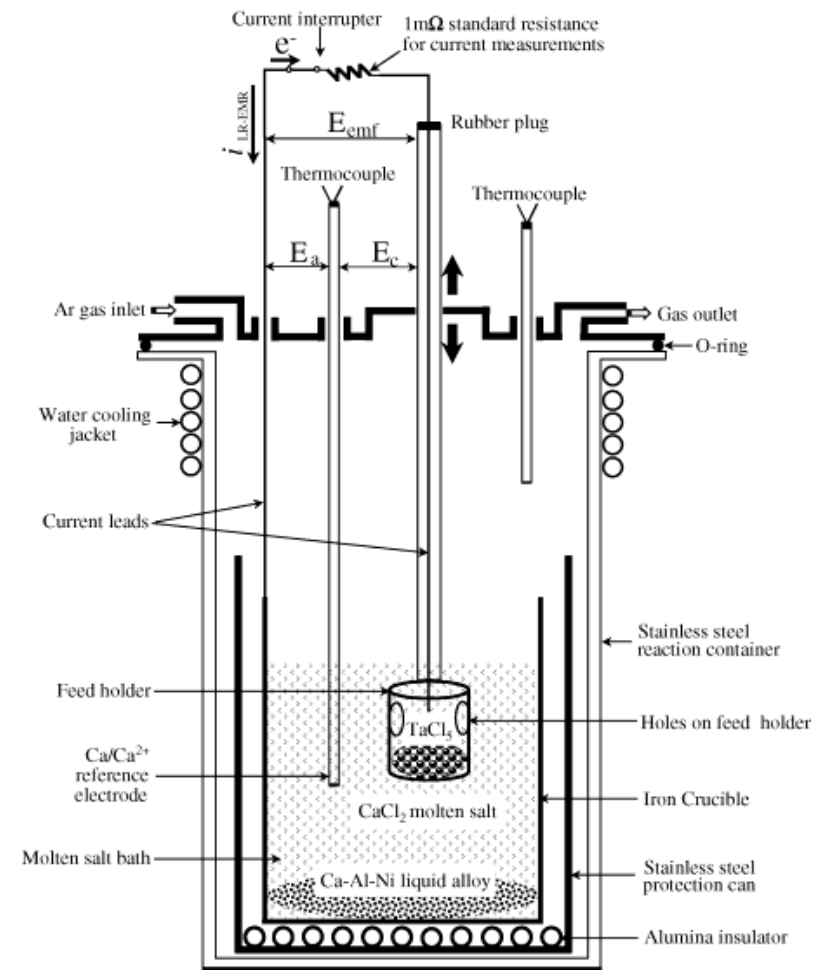

Fig. 3 Schematic diagram of the experimental apparatus for semi-continuous production of tantalum powder by caliothermic reduction of $\mathrm{TaCl}_{5}$.

designed. $\mathrm{TaCl}_{5}$ feedstock in a steel holder was charged into a bath of molten salt, and was reduced by calcium reductant placed at the bottom of a crucible as a liquid $\mathrm{Ca}-\mathrm{Al}-\mathrm{Ni}$ alloy. Figure 3 illustrates a LR-EMR condition where the metallic holder containing $\mathrm{TaCl}_{5}$ and the crucible containing the $\mathrm{Ca}-\mathrm{Al}-\mathrm{Ni}$ alloy are electrically connected through an external circuit. Nickel and aluminum were alloyed with calcium metal reductant not only to increase its density and fluidity, but also to function as a tracer for monitoring the transport of the metallic reductant. In this case, the reactions described by eqs. (3) and (4) occur without physical contact with $\mathrm{TaCl}_{5}$ and calcium. Electrons, produced by the oxidation of calcium according to eq. (4), travel along the external circuit to the feed holder containing $\mathrm{TaCl}_{5}$, and pure tantalum metal powder can be obtained. This reaction corresponds to the reaction schematically illustrated in Fig. 1(b). The amounts of materials used in each reaction cell are listed in Table 1. A Ca-20 mol\%Al-10 mol\% Ni alloy weighing about $31.4 \mathrm{~g}$ was first charged into an iron crucible with a $34 \mathrm{~mm}$ inner diameter (I.D.). The alloy contained $0.56 \mathrm{~mol}$ calcium. Then $\mathrm{CaCl}_{2}$ salt, weighing a total of about $890 \mathrm{~g}$, was added. A steel tube with a $16.5 \mathrm{~mm}$ I.D. containing $7.16 \mathrm{~g}$ of $\mathrm{TaCl}_{5}$ was used as a feed holder. This feedstock contained $0.02 \mathrm{~mol} \mathrm{TaCl}_{5}$. Holes, located on the side of the feed holder and above the feed level, permitted ions to be transported through the salt phase and to maintain charge neutrality during the reaction.

\subsection{Experimental procedure}

The salt cell with reductant was charged into a stainless steel chamber with a $96 \mathrm{~mm}$ I.D. After gas tightness of the reaction chamber was verified under vacuum at $200 \mathrm{~Pa}$, it was then filled with argon gas three times and then heated under argon atmosphere. When the cell temperature was stabilized
Table 1 Experimental conditions of the calciothermic reduction and EMR of tantalum at $1123 \mathrm{~K}$.

\begin{tabular}{|c|c|c|c|c|c|}
\hline \multirow{3}{*}{$\begin{array}{c}\text { Exp. } \\
\text { condition }\end{array}$} & \multirow{3}{*}{$\begin{array}{l}\text { Exp. } \\
\text { runs }\end{array}$} & \multicolumn{3}{|c|}{ Amount of material used, $w_{\mathrm{i}} / \mathrm{g}$} & \multirow{3}{*}{ Results } \\
\hline & & Feedstock & Reductant* $^{*}$ & $\underline{\text { Salt }}$ & \\
\hline & & $\mathrm{TaCl}_{5}$ & $\mathrm{Ca}-\mathrm{Al}-\mathrm{Ni}$ alloy & $\mathrm{CaCl}_{2}$ & \\
\hline \multirow{12}{*}{ EMR } & D1 & 7.1 & 31.5 & 890 & Figs. $4,5,6,7$ \\
\hline & D2 & 7.2 & & & Fig. 5 \\
\hline & D3 & 7.2 & & & Figs. 5, 6, 7 \\
\hline & $\mathrm{D} 4^{\$}$ & 7.2 & 3.9 & & Figs. 5, 6, 7 \\
\hline & E1 & 7.2 & 31.8 & 889 & \\
\hline & E2 & 7.3 & & & \\
\hline & E3 & 7.2 & & & \\
\hline & $\mathrm{E} 4^{\$}$ & 7.1 & 4 & & \\
\hline & $\mathrm{F} 1$ & 7.2 & 31.4 & 888 & Figs. $4,5,6,7$ \\
\hline & $\mathrm{F} 2$ & 7.2 & & & \\
\hline & F3 & 7.2 & & & \\
\hline & $\mathrm{F} 4^{\$}$ & 7.2 & 3.9 & & \\
\hline \multirow{3}{*}{$\begin{array}{l}\text { Calciothermic } \\
\text { reduction }\end{array}$} & $X$ & 7.3 & 10.5 & 89 & Figs. 5, 6, 7 \\
\hline & $\mathrm{Y}$ & 7.2 & 10.7 & 90 & \\
\hline & $\mathrm{Z}$ & 7.2 & 10.4 & 88 & \\
\hline
\end{tabular}

*: $\mathrm{Ca}-20 \mathrm{~mol} \% \mathrm{Al}-10 \mathrm{~mol} \% \mathrm{Ni}$ alloy was used.

$\$$ : Reductant was freshly recharged $4 \mathrm{~g}$ of $\mathrm{Ca}-\mathrm{Al}-\mathrm{Ni}$ alloy after Exp. run 3.

at $1123 \mathrm{~K}$, the feed holder containing $\mathrm{TaCl}_{5}$ powder located in the cooling zone was submerged into the molten salt bath.

For Exps. \#D2, D3, and D4, the feed holder was recharged each time with the same amount of a fresh $\mathrm{TaCl}_{5}$ feedstock used in Exp. \#D1, but the bath was successively reused without replenishment. This scheme was intended to test the feasibility of a semi-continuous operation. The stainless steel feed holders were used in Exps. \#F1, F2, F3, F4 and Z.

The EMR results were compared with some experimental results of the conventional calciothermic reduction, in which feed and reductant are physically mixed.

During the experiment, the electrochemical potential of the feed holder was continuously monitored with respect to the crucible, which acted as a $\mathrm{Ca} / \mathrm{Ca}^{2+}$ reference. In the experiments with the condition of \#D1 and \#F1, current flow between the crucible (anode) and the feed holder (cathode) through the external circuit was monitored by measuring voltage across a $1 \mathrm{~m} \Omega$ standard resistance. The external current was periodically interrupted to measure the voltage between electrodes, $E_{\mathrm{LR}-\mathrm{EMR}}$. Thus, the driving force of the EMR was monitored as a function of time. All analogue data, e.g. electrode potentials, were continuously monitored by an X-Y recorder and a digital multi-meter (DMM) with multi-channel scanner. The reduction reaction was conducted for $7.2 \mathrm{ks}$. Then, retrieving the feed holders from the molten salt terminated the reduction. The feed holders were taken out from the chamber after cooling in argon atmosphere for about $43 \mathrm{ks}$. After the end of the reaction, the feed holders and solidified salt were mechanically recovered.

The metal deposit in powder form was obtained by dissolving the salt in distilled water. To dissolve attached the salt, the solid deposit obtained after reduction was leached at $323 \mathrm{~K}$ for $10.8 \mathrm{ks}$ in a $30 \%$ acetic acid solution, followed by washing with distilled water. Then the deposit was leached again at $323 \mathrm{~K}$ for $10.8 \mathrm{ks}$ with a $30 \% \mathrm{HNO}_{3}-30 \% \mathrm{HCl}$ solution. 
The morphology of the deposit obtained from various locations was observed with a scanning electron microscope (SEM). The impurity content of the powder deposit was determined by X-ray fluorescence (XRF), energy dispersive $\mathrm{X}$-ray (EDX) and inductively coupled plasma (ICP) analysis. $\mathrm{X}$-ray diffraction (XRD) analysis was conducted to identify the phases in the deposit.

\section{Results and Discussion}

The variation of the external current with reaction time during the LR-EMR experiments of \#D1 and F is given in Figs. 4(a) and (b), respectively. Time zero corresponds to the moment when the feed was charged into the salt bath. The external current of 1.0 and 1.2 amps was detected immediately after introducing the feed into the salt bath in a respective experiment. In the LR-EMR tests, $\mathrm{TaCl}_{5}$ feedstock holders were used, iron holder in Exp. \#D1 of Fig. 4(a) and stainless steel holder in Exp. \#F1 of Fig. 4(b), respectively.

$\mathrm{TaCl}_{5}$ feed holders were immersed $20 \mathrm{~mm}$ in depth into the molten salt during the LR-EMR experiment, because the external current values vary depending on the immersed depth of the feed holder in the molten salt. Although the current and time scale were found to vary, the same patterns of variation in the external current with reaction time was observed, and the existence of EMR was confirmed.

The total electrical charge $(Q)$ passing through the exter-
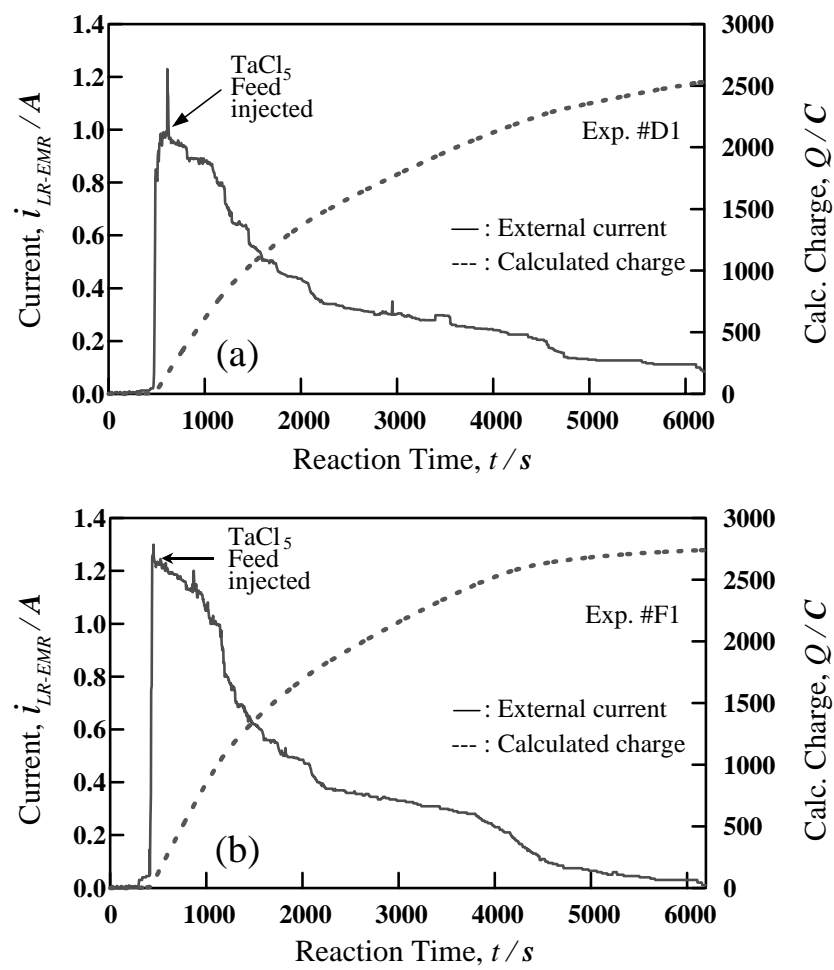

Fig. 4 Results in the calciothermic reduction of semi-continous production tantalum powder by $\mathrm{TaCl}_{5}$ in various conditions at $1123 \mathrm{~K}$. (a) Change of observed current and calculated charge passing through an external circuit as a function of time under LR-EMR condition using iron feed holder (Exp. \#D1). (b) Change of observed current and calculated charge passing through an external circuit as a function of time under LR-EMR condition using stainless steel feed holder (Exp. \#F1) specified in Table 2. nal circuit was estimated by integrating the current $\left(i_{\text {LR-EMR }}\right)$ with time. About 2500 and 2700 coulombs (C) for LM-EMR in Exp. \#D1 of Fig. 4(a), and in Exp. \#F1 of Fig. 4(b) were obtained, respectively.

A total charge of about $9650 \mathrm{C}$ is theoretically required to reduce $7.16 \mathrm{~g}$ of $\mathrm{TaCl}_{5}$ completely to tantalum metal. Therefore, only $26 \%$ and $28 \%$ of $\mathrm{TaCl}_{5}$ is reduced by LR-EMR in the two experiments. These values were small compared to the results by Okabe and Sadoway) where $37 \%$ of $\mathrm{K}_{2} \mathrm{TaF}_{7}$ was reduced by sodium through an external circuit, and to those by Park et al. ${ }^{10)}$ where $30 \%$ of $\mathrm{TaCl}_{5}$ was reduced by magnesium at $1073 \mathrm{~K}$. However, these values were bigger than those obtained from the calciothermic reduction of $\mathrm{Nb}_{2} \mathrm{O}_{5}$ where it was only $3 \%-15 \%,{ }^{11)}$ and those obtained from semi-continuous production of niobium powder by magnesiothermic reduction of $\mathrm{Nb}_{2} \mathrm{O}_{5}$ where it was $3 \%-4 \% .{ }^{18)}$ The small values for the LR-EMR ratio might be attributed to the electronic conductivity of the molten salt or mobility of ions in the molten salts. The observed external current is much lower than the real amount of LR-EMR because it was very difficult to avoid the current leak on the surface of the molten salt saturated with metallic calcium under highly reducing conditions at elevated temperatures, so that good reproducibility of the current profies could not be obtained. The loss of $\mathrm{TaCl}_{5}$ feedstock might also be significant because of its high vapor pressures at $1123 \mathrm{~K}$ (calculated boiling point for pure $\mathrm{TaCl}_{5}$ is $\left.506 \mathrm{~K}\right) .{ }^{19}$ )

The XRF and ICP analysis results for chemical composition of tantalum powder deposited in all the conditions are listed in Table 2. The analytical results indicate that there was a very small few amount of chlorine in the deposit, and reduction to metallic tantalum was completed during experiment. The tantalum metal powders obtained in Exp. \#D1 of Fig. 3(a) and Exp. \#F1 of Fig. 3(b) in the LR-EMR conditions had a purity of $95 \%$ and $93 \%$ Ta, but the purity dropped to $87 \%$ and 89\% Ta in Exp. \#D3 of Fig. 3(a) and Exp. \#F3 of Fig. 3(b), respectively, as the run number using the same salt increased. The purity of the tantalum deposit was again increased to $93 \%$ and $91 \%$ in Exp. \#D4 of Fig. 3(a) and Exp. \#F4 of Fig. 3(b) after recharging the reductant into the molten salt. The drop in the purity of the tantalum powder was, to some extent, attributed to an insufficient amount of calcium used in subsequent operations.

In Table 2, phases identified by XRD in the tantalum powder deposits are listed together with the LR-EMR ratio calculated from the external current during each experiment. Although the reductant contained $20 \mathrm{~mol} \% \mathrm{Al}$ and $10 \mathrm{~mol} \% \mathrm{Ni}$, and tantalum is known to have a very strong affinity for aluminum and nickel, a trace amount of aluminum and nickel was detected in the tantalum deposit. The result, in which pure tantalum powder with low nickel and aluminum content were obtained, shows that the reduction proceeded without physical contact between the feed and reductant.

Due to the limited holder size employed in this work, it was difficult to obtain very high purity tantalum powder. However, the results clearly indicate that the reduction of tantalum took place not by the physical contact of $\mathrm{TaCl}_{5}$ with $\mathrm{Ca}-\mathrm{Al}-\mathrm{Ni}$ alloy reductant, but by the electron transfer through an external circuit at different locations.

The SEM images of the acid-treated deposits obtained in 
Table 2 Results of XRF, ICP, EMR ratio and XRD identified phases of analysis of metal powder obtained in various conditions at $1123 \mathrm{~K}$.

\begin{tabular}{|c|c|c|c|c|c|c|c|c|c|c|}
\hline \multirow{2}{*}{$\begin{array}{c}\text { Exp. } \\
\text { condition }\end{array}$} & \multirow{2}{*}{$\begin{array}{l}\text { Exp. } \\
\text { Runs. }\end{array}$} & \multicolumn{7}{|c|}{$\mathrm{XRF}$ and ICP composition analysis, $X_{\mathrm{i}}$ (mass $\%$ ) } & \multirow{2}{*}{$\begin{array}{l}\text { LR-EMR } \\
\text { ratio }(\%)\end{array}$} & \multirow{2}{*}{ XRD identified phases } \\
\hline & & $\mathrm{Ta}$ & $\mathrm{Ca}$ & $\mathrm{Al}$ & $\mathrm{Ni}$ & $\mathrm{Fe}$ & $\mathrm{Cl}$ & $\mathrm{Cr}$ & & \\
\hline \multirow{11}{*}{ EMR } & D1 & 95 & $0.2[0.7]$ & $0.8[0.9]$ & $0.1[0.3]$ & 4.2 & n.d. ${ }^{\wedge}$ & n.d. & 26 & $\mathrm{Ta}$ \\
\hline & D3 & 87 & $1.5[1.9]$ & $2.1[2.8]$ & $0.7[0.9]$ & 8.8 & 0.3 & n.d. & 21 & $\mathrm{Ta}, \mathrm{Fe}_{5} \mathrm{Ta}_{3},\left(\mathrm{Fe}_{7} \mathrm{Ta}_{3}\right)$ \\
\hline & D4 & 93 & $0.4[1.0]$ & $0.9[0.7]$ & $0.2[0.1]$ & 5.3 & 0.2 & n.d. & 18 & $\mathrm{Ta}, \mathrm{Fe}_{5} \mathrm{Ta}_{3}$ \\
\hline & E1 & 94 & $0.5[1.0]$ & n.d. [1.1] & n.d. $[0.2]$ & 5.6 & n.d. & n.d. & 23 & $\mathrm{Ta}, \mathrm{Fe}_{5} \mathrm{Ta}_{3}$ \\
\hline & E2 & 92 & $0.2[0.1]$ & $0.3[1.1]$ & $0.3[0.6]$ & 7.5 & n.d. & n.d. & 17 & $\mathrm{Ta}, \mathrm{Fe}_{5} \mathrm{Ta}_{3}$ \\
\hline & E3 & 88 & $1.4[1.1]$ & $0.7[1.0]$ & $0.5[0.4]$ & 8.6 & 0.5 & n.d. & 19 & $\mathrm{Ta}, \mathrm{Fe}_{5} \mathrm{Ta}_{3},\left(\mathrm{Fe}_{7} \mathrm{Ta}_{3}\right)$ \\
\hline & $\mathrm{E} 4$ & 91 & $0.7[1.6]$ & $1.3[1.5]$ & $0.1[0.1]$ & 6.7 & 0.3 & n.d. & 21 & $\mathrm{Ta}, \mathrm{Fe}_{5} \mathrm{Ta}_{3}$ \\
\hline & $\mathrm{F} 1^{*}$ & 93 & $0.5[0.9]$ & $0.3[1.1]$ & n.d. $[0.2]$ & 4.4 & 0.1 & 1.4 & 28 & $\mathrm{Ta}, \mathrm{Fe}_{5} \mathrm{Ta}_{3}$ \\
\hline & $\mathrm{F} 2^{*}$ & 91 & $1.1[1.3]$ & $1.0[1.8]$ & $0.3[0.9]$ & 4.8 & 0.1 & 1.3 & 24 & $\mathrm{Ta}, \mathrm{Fe}_{5} \mathrm{Ta}_{3}$ \\
\hline & F3* & 89 & $1.3[1.1]$ & $1.4[2.1]$ & $0.8[1.1]$ & 5.8 & 0.2 & 1.8 & 22 & $\mathrm{Ta}, \mathrm{Fe}_{5} \mathrm{Ta}_{3},\left(\mathrm{Fe}_{7} \mathrm{Ta}_{3}\right)$ \\
\hline & $\mathrm{F} 4^{*}$ & 91 & $0.8[0.4]$ & $0.9[0.8]$ & $0.4[0.8]$ & 5.4 & 0.2 & 1.5 & 18 & $\mathrm{Ta}, \mathrm{Fe}_{5} \mathrm{Ta}_{3}$ \\
\hline \multirow{3}{*}{$\begin{array}{c}\text { Calciothermic } \\
\text { reduction }\end{array}$} & $\mathrm{X}$ & 92 & $5.2[5.8]$ & $2.1[1.2]$ & $0.1[0.5]$ & 0.2 & n.d. & n.d. & - & $\mathrm{Ta}, \mathrm{Fe}_{5} \mathrm{Ta}_{3}$ \\
\hline & $\mathrm{Y}$ & 93 & $5.5[6.4]$ & $1.6[1.8]$ & $0.2[0.4]$ & n.d. & n.d. & n.d. & - & $\mathrm{Ta}, \mathrm{Fe}_{5} \mathrm{Ta}_{3}$ \\
\hline & $\mathrm{Z}$ & 92 & $5.7[5.2]$ & $1.9[1.4]$ & n.d. [0.7] & n.d. & n.d. & n.d. & - & $\mathrm{Ta}, \mathrm{Fe}_{5} \mathrm{Ta}_{3}$ \\
\hline
\end{tabular}

$\wedge$ : n.d. "represents below detection limit of XRF analysis (about 0.01 mass \%).

*: Stainless steel sample holder was used.

[ ]: Determined by ICP-AES analysis.

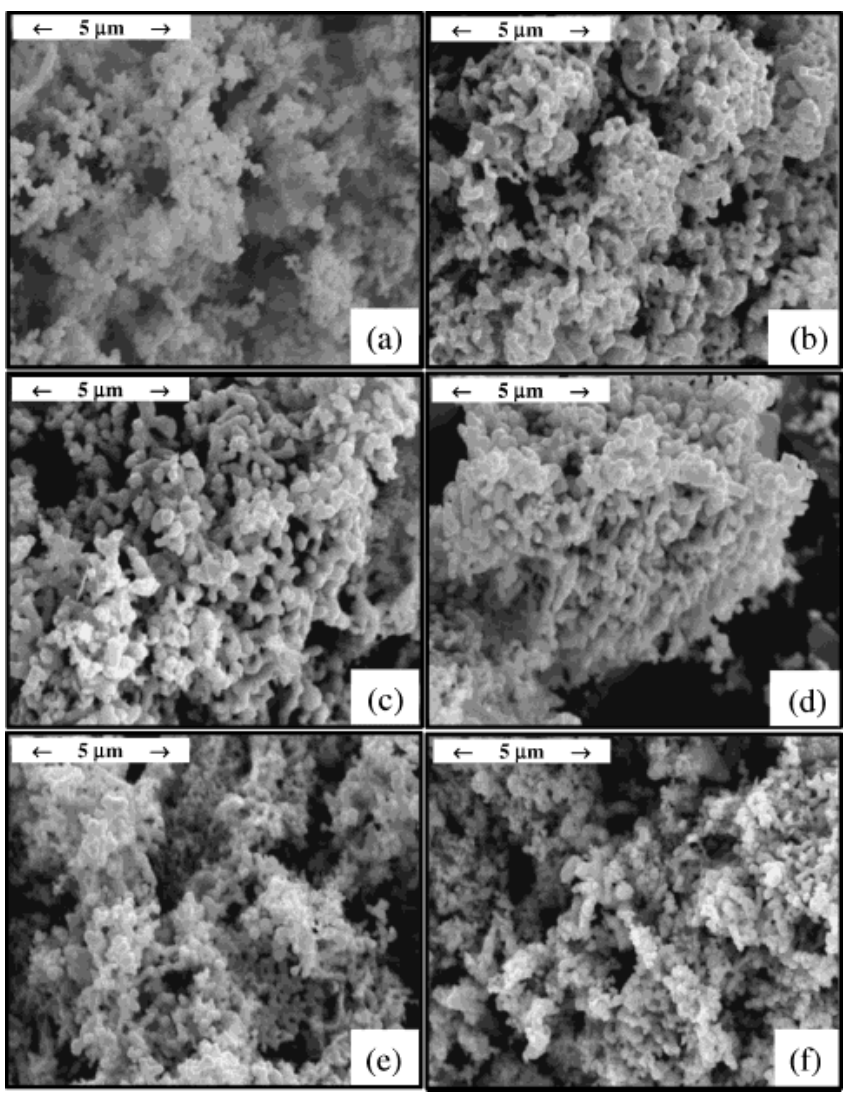

Fig. 5 Scanning electron micrographs of tantalum deposit obtained in various conditions at $1123 \mathrm{~K}$. (a) Exp. \#D1 (b) Exp. \#D2 (c) Exp. \#D3 (d) Exp. \#D4 (e) Exp. \#X (f) Exp. \#F1.

various conditions are given in Fig. 5. The images of the acid-treated deposits obtained from the LR-EMR experiments on the semi-continuous production conditions (Exps. \#D14) of $\mathrm{TaCl}_{5}$ by calcium reductant are shown from Figs. 5(a) to (d). Powder shown in Fig. 5(e) is the acid-treated de- posits obtained from the calciothermic reduction condition (see Exps. \#X, Y, Z in Table 1). The SEM image shown in Fig. 5(f) is the acid-treated deposits obtained from the LREMR experiment using a stainless steel feed holder. The morphology of the powder deposit in the feed holder is similar to that obtained in the conventional metallothermic reduction, and in the previous EMR experiments on the reduction of $\mathrm{TaCl}_{5}$ by magnesium reductant. ${ }^{10)}$

The size of the tantalum powder grains obtained from the second, the third and the fourth experiments using the same bath and reductant was slightly larger in the average diameter, while, metal powders with the same morphology but a lower purity were obtained. The mean size of the tantalum powder grains obtained from the semi-continuous production process of the EMR experiment is about $0.2-0.3 \mu \mathrm{m}$ and finer compared with about $0.4-0.6 \mu \mathrm{m}$ obtained from the metallothermic reduction experiment.

X-ray diffraction patterns of tantalum metal powder by the calciothermic reduction and the acid-treated deposits obtained in LR-EMR experiments on the semi-continuous production conditions (Exps. \#D1-4) of $\mathrm{TaCl}_{5}$ by calcium reductant are given in Fig. 6. The deposits obtained in this study were identified to be a pure tantalum metal. However, as shown in Fig. 6(e), the deposit contains some Fe-Ta intermetallic compound impurities when using a stainless steel feed holder (Exp. \#F1).

EDX spectrum patterns of tantalum metal powder by the calciothermic reduction and the acid-treated deposits obtained from the LR-EMR experiment on the semi-continuous production conditions (Exps. \#D1, D3, D4 and X) of $\mathrm{TaCl}_{5}$ by calcium reductant are given in Fig. 7.

Phase diagrams are often used to discuss reaction pathways during metallothermic reduction. Although the phase diagrams with composition scales are useful in understanding the solubility and phase relationships, they do not pro- 

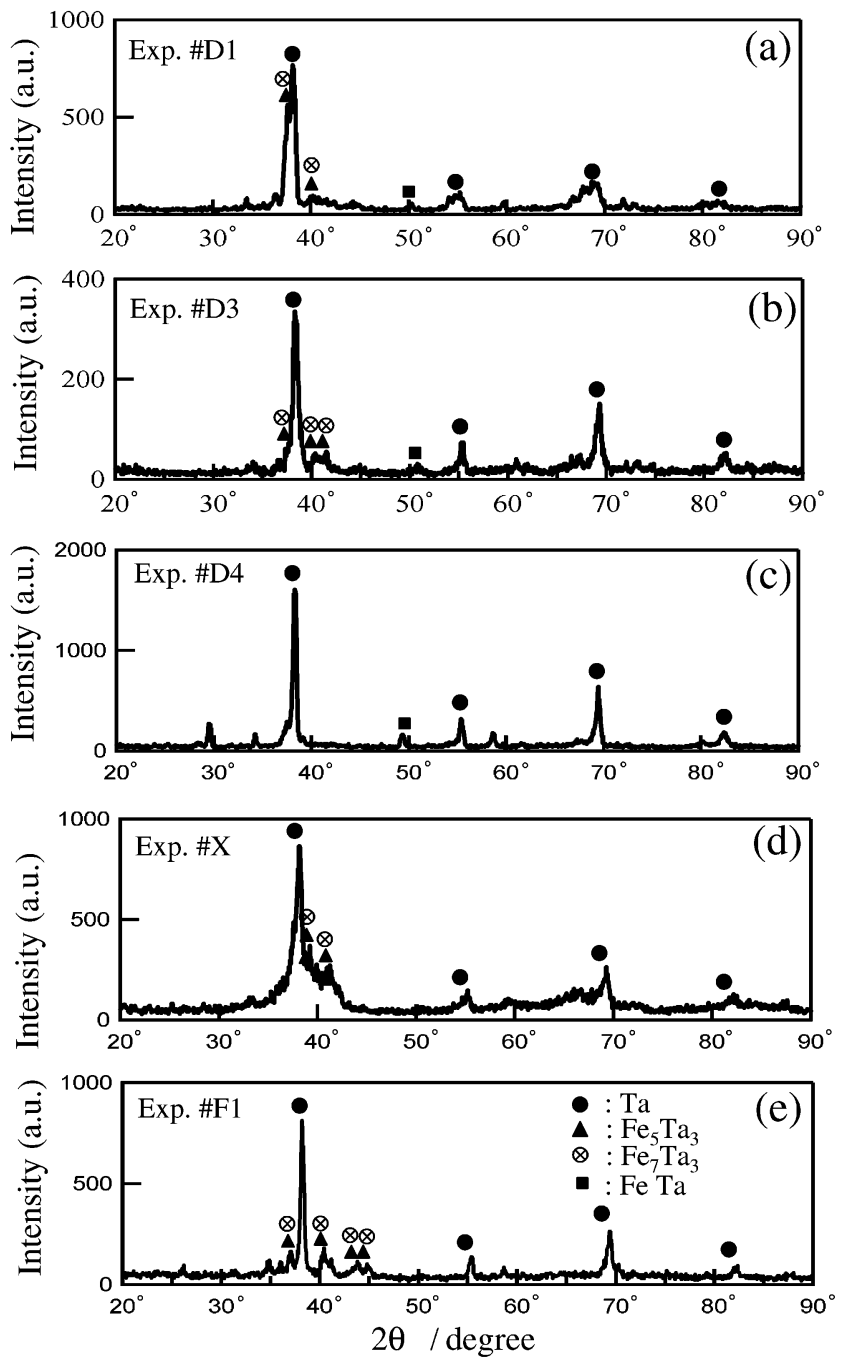

Fig. 6 X-ray diffraction patterns of samples obtained from feed holder in various conditions at $1123 \mathrm{~K}$. (a) Exp. \#D1 (b) Exp. \#D3 (c) Exp. \#D4 (d) Exp. \#X (e) Exp. \#F1.

vide enough information about reaction pathways, especially in EMR systems. This is mainly because the thermodynamic equilibrium end point of the reaction is a three-phase triangle, e.g. $\mathrm{Ta} / \mathrm{Ca} / \mathrm{CaCl}_{2}$ (equilibrium). To understand the local reactions, it is useful to know the chemical potentials of all components along various phase fields. Therefore, a threedimensional (3D) chemical potential diagram for the $\mathrm{Ta}-\mathrm{Ca}-$ $\mathrm{Cl}$ system at $1123 \mathrm{~K}$ is constructed and shown in Fig. 8(a), where each single-phase field is represented by a surface, twophase equilibrium by a line, and three-phase equilibrium by a point. The values of thermodynamic data for constructing the diagram are shown in Table 3.

The chemical potentials of the starting material $\left(\mathrm{TaCl}_{5}\right)$, calcium reductant, and reaction endpoint are indicated by arrows in Fig. 8(a). In Fig. 8(a), the stability region of each phase is calculated assuming unit activity as a first approximation. In the present study, however, activity for each species is not always unity. For example, some compounds dissolve in molten $\mathrm{CaCl}_{2}$. It is worth mentioning that even if the activity of a chemical species decreases to 0.01 , the stability limit of the species shifts by approximately 2 units in the figure. This change is relatively small compared to the scale employed
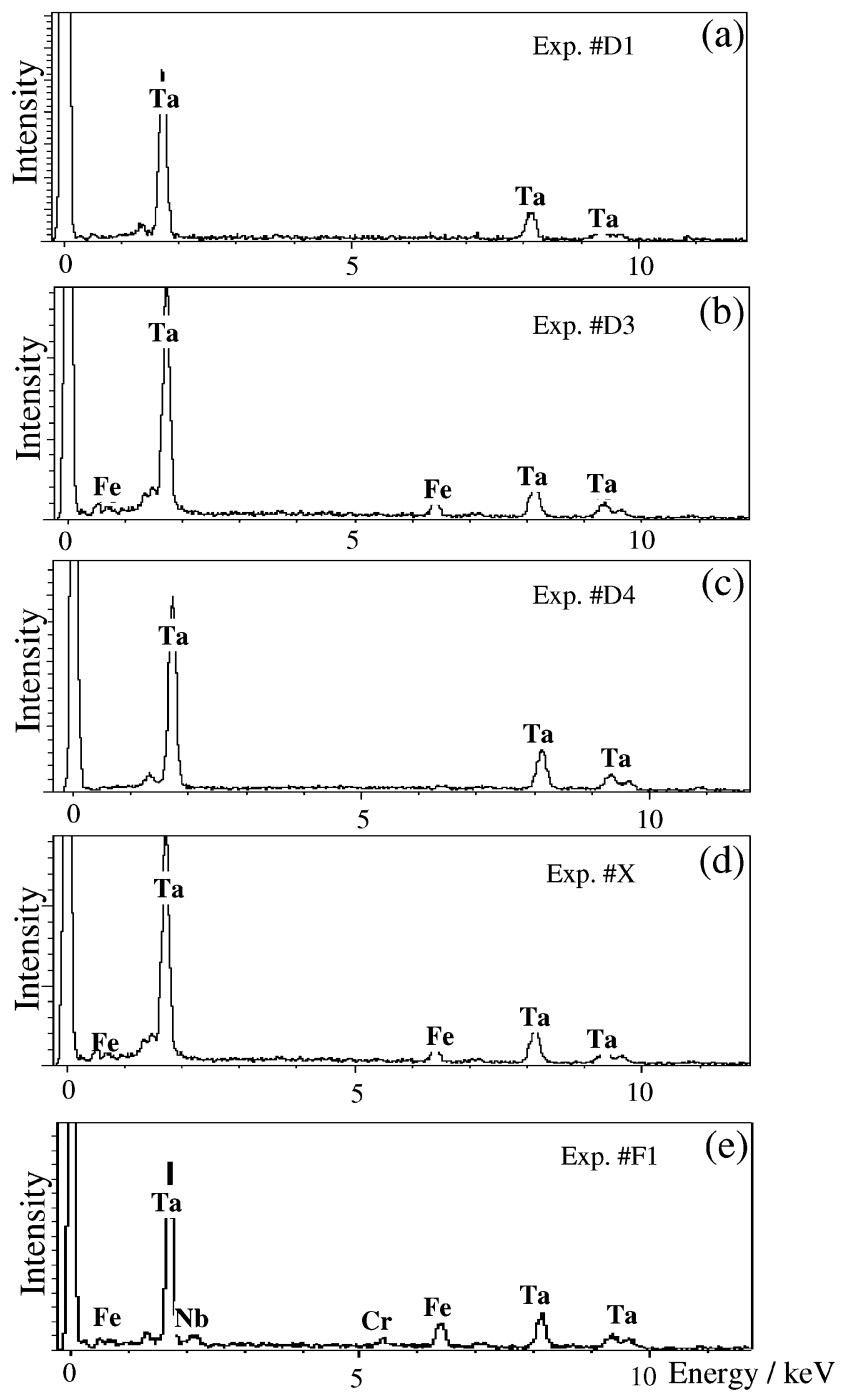

Fig. 7 EDX patterns of the obtained powder after acid treatment. (a) Exp. \#D1 (b) Exp. \#D3 (c) Exp. \#D4 (d) Exp. \#X (e) Exp. \#F1.

in this work. Therefore, any change in the main points of discussion is not required with the assumption about unit activity. Instantaneous values of chemical equilibrium between phases can be expressed as points in this figure, and all reaction pathways can be drawn as "curves", starting from the initial feed to the reaction endpoint along the surface of polyhedrons. Therefore, this 3D chemical potential diagram provides not only instantaneous information of phase relationships but also possible reaction pathways during LR-EMR.

After the completion of calciothermic reduction of $\mathrm{TaCl}_{5}$, the chemical potential of the system reaches its endpoint at the $\mathrm{Ta} / \mathrm{Ca} / \mathrm{CaCl}_{2}$ equilibrium, shown as point “(1)". Driving the reduction process, the chemical potentials of the $\mathrm{TaCl}_{5}$ phase change from point "a" to "(1)", and those of the calcium change from " $b$ " to "(1)". If molten $\mathrm{CaCl}_{2}$ dissolves either $\mathrm{TaCl}_{5}$ or metallic calcium, reaction (2) will proceed by the diffusion of the feed and/or reductant in the molten $\mathrm{CaCl}_{2}$.

Figure $8(\mathrm{~b})$ is a schematic representation of the reduction mechanism for LR-EMR, consistent with the chemical potential diagram. One can understand from the diagram that the metal/molten salt interface, which corresponds to the line connecting path "(1)" and "(2)" in Fig. 8(a), connecting the two 

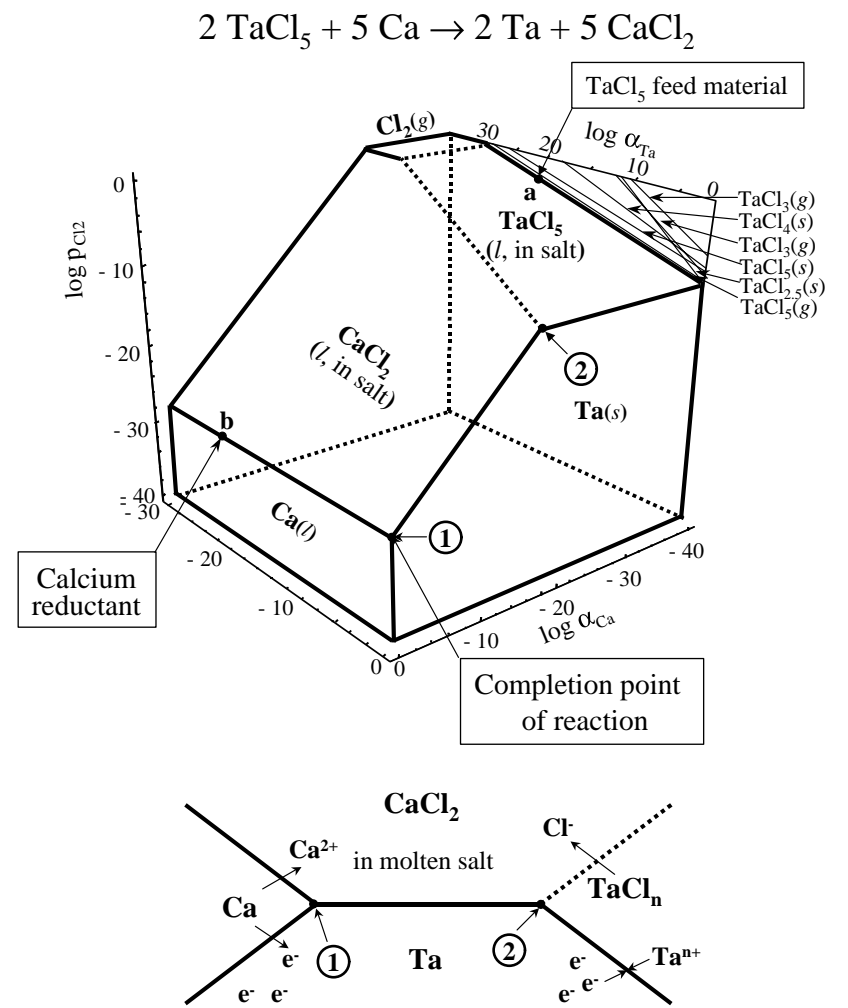

Fig. 8 (a) Three-dimensional chemical potential diagram for the system $\mathrm{Ta}-\mathrm{Ca}-\mathrm{Cl}$ at $1123 \mathrm{~K}$. (b) Depiction of the reaction pathway for the LR-EMR, consistent with the phase diagram.

Table 3 The standard Gibbs energies for the reaction at $1123 \mathrm{~K}$ discussed in this study. The values are calculated by interpolation and extrapolation of data by Brain. ${ }^{19)}$

\begin{tabular}{clc}
\hline Eq. no. & Reactions & $\begin{array}{c}\text { The std. Gibbs energy } \\
\text { at } 1123 \mathrm{~K}, \\
\Delta G^{\circ} / \mathrm{kJ} \cdot \mathrm{mol} \mathrm{Cl}_{2}^{-1}\end{array}$ \\
\hline 1 & $\mathrm{Ta}(s)+\mathrm{Cl}_{2}(g) \rightarrow \mathrm{TaCl}_{2}(g)$ & $-104^{\mathrm{a}}$ \\
2 & $4 / 5 \mathrm{Ta}(s)+\mathrm{Cl}_{2}(g) \rightarrow 4 / 5 \mathrm{TaCl}_{2.5}(g)$ & $-230^{\mathrm{b}}$ \\
3 & $2 / 3 \mathrm{Ta}(s)+\mathrm{Cl}_{2}(g) \rightarrow 2 / 3 \mathrm{TaCl}_{3}(s)$ & $-208^{\mathrm{b}}$ \\
4 & $2 / 3 \mathrm{Ta}(s)+\mathrm{Cl}_{2}(g) \rightarrow 2 / 3 \mathrm{TaCl}_{3}(g)$ & $-192^{\mathrm{a}}$ \\
5 & $2 / 5 \mathrm{Ta}(s)+\mathrm{Cl}_{2}(g) \rightarrow 2 / 5 \mathrm{TaCl}_{5}(l)$ & $-194^{\mathrm{b}}$ \\
6 & $2 / 5 \mathrm{Ta}(s)+\mathrm{Cl}_{2}(g) \rightarrow 2 / 5 \mathrm{TaCl}_{5}(g)$ & $-225^{\mathrm{a}}$ \\
\hline 7 & $2 \mathrm{Ca}(l)+\mathrm{Cl}_{2}(g) \rightarrow 2 \mathrm{CaCl}_{2}(g)$ & $-394^{\mathrm{a}}$ \\
8 & $\mathrm{Ca}(l)+\mathrm{Cl}_{2}(g) \rightarrow \mathrm{CaCl}_{2}(l)$ & $-626^{\mathrm{a}}$ \\
9 & $\mathrm{Ca}(l)+\mathrm{Cl}_{2}(g) \rightarrow \mathrm{CaCl}_{2}(g)$ & $-497^{\mathrm{a}}$ \\
\hline
\end{tabular}

a: The values are calculated by interpolation.

b: The values are calculated by extrapolation.

three-phase fields plays an important role in the calciothermic reduction process. Existence of $\mathrm{Ta}(s) / \mathrm{CaCl}_{2}(l$, molten salt) interface can facilitate the reduction process, and in this case, the reductant calcium does not necessarily make physical contact with the tantalum chlorides: rather, the major process involves electron and ion transfer. Although EMR is proven important to the reduction process, the conventional reduction mechanism of tantalum proposed in the past, should not be excluded because the direct reaction between feed and reductant appears to be a significant factor especially for the system investigated. Further discussion of this topic has been given elsewhere. ${ }^{4,14,15)}$

\section{Conclusions}

The results from the calciothermic reduction of $\mathrm{TaCl}_{5}$ suggest that the concept of an electronically mediated reaction plays an important role in the caliothermic reduction process. The reduction can proceed without physical contact between reactants when an electrical pathway is provided for the electron transfer between electrochemical oxidation and reduction sites. The experimental results demonstrated the possibility of continuous production of tantalum metal powders by the EMR without direct physical contact between the reactants. The isothermal chemical potential diagram is useful for discussing the metal/molten salt interface and reduction mechanism of $\mathrm{TaCl}_{5}$ by calcium. The powder obtained from the EMR experiment has finer particles than those obtained from the metallothermic reduction process. This approach may be applied to develop a semi-continuous process to produce a pure tantalum metal powder.

\section{Acknowledgements}

This work was supported by the Research Center of Industrial Technology, Engineering Research Institute at Chonbuk National University.

\section{REFERENCES}

1) C. K. Gupta and P. K. Jena: J. Less-Common Met. 8 (1965) 90-98.

2) M. A. Hunter: J. Metals 5 (1953) 130-132.

3) W. Köch and P. Paschen: J. Metals (October 1989) 33-39.

4) T. H. Okabe and D. R. Sadoway: J. Mate. Res. 13 (1998) 3372-3377.

5) T. Uda, T. H. Okabe, E. Kasai and Y. Waseda: J. Japan Inst. Metals 61 (1997) 602-609.

6) T. Uda, T. H. Okabe and Y. Waseda: J. Japan Inst. Metals 62 (1998) 76-84.

7) T. Uda, T. H. Okabe and Y. Waseda: J. Japan Inst. Metals 62(1998) 796-802.

8) T. H. Okabe, T. Uda and Y. Waseda: Shigen-to-Sozai (J. Min. Mater. Process. Inst. Jpn.) 114 (1998) 573-579.

9) T. Uda, T. H. Okabe, Y. Waseda and K. T. Jacob: J. Alloys Compd. 284 (1999) 282-288.

10) I. Park, T. H. Okabe and Y. Waseda: J. Alloys Compd. 280 (1998) 265272.

11) T. H. Okabe, I. Park, K. T. Jacob and Y. Waseda: J. Alloys Compd. 288 (1999) 200-210.

12) F. S. Wartman, D. H. Baker, J. R. Nettle and V. E. Homme: J. Electrochem. Soc. 101 (1954) 507-513.

13) C. K. Gupta and P. K. Jena: Trans. Metall. Soc. AIME 230 (1964) 14331438.

14) T. H. Okabe, T. Uda, E. Kasai and Y. Waseda: J. Japan Inst. Metals 61 (1997) 610-618.

15) T. H. Okabe and Y. Waseda: J. Metals (JOM) 49 (1997) 28-32.

16) E. D. Eastman, D. D. Cubicciotti and C. D. Thurmond: L. L. Quill (Ed.), Chemistry and Metallurgy of Miscellaneous Materials, (McGraw-Hill, New York, 1950) pp. 10, paper 2.

17) K. M. Axler and G. L. Depoorter: Mater. Sci. Forum 73-75 (1991) 1924.

18) I. Park, T. H. Okabe, Y. Waseda, H. S. Yu and O. Y. Lee: Mater. Trans. 42 (2001) 850-855.

19) I. Barin: Thermochemical Data of Pure Substances, (VCH, Weinheim, 1989) pp. 1440-1463. 